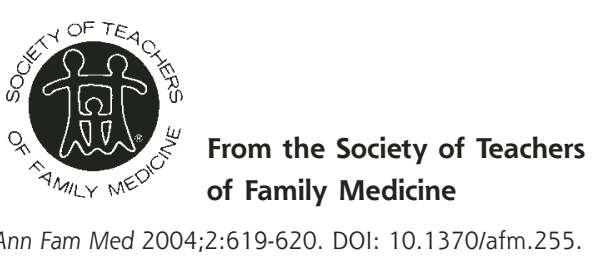

\section{STFM AND THE IMPLEMENTATION OF THE FUTURE OF FAMILY MEDICINE PROJECT}

\section{Status of Medical Education}

The Future of Family Medicine Project ${ }^{1}$ was conceived as a strategic process to evaluate and reengineer the discipline upon recognizing fundamental flaws in the fragmented US health care systems and the need to address the needs of patients in a changing health care environment. To address changing patient demands, family medicine educators must shape the education and training of future family physicians to respond to those needs.

Other members of the medical education community have begun to recognize that it is time to reassess how physicians have traditionally been taught. A recent report of the Ad Hoc Committee of Deans, The State of Medical Education, described "clinical education as not having kept pace with or been responsive enough to shifting patient demographics and desires, changing health system expectations, evolving practice requirements and staffing arrangements, new information, a focus on improving quality, or new technologies." ${ }^{\prime 2}$

Other academic leaders have partnered with the Robert Wood Johnson Foundation to address chronic illness care as part of the Take Care to Learn: Teaching Clinical Care Management project. ${ }^{3}$ Each of 9 institutions focused on asthma or diabetes management and crafted a program to improve patient outcomes. The programs teach residents and nurse practitioner students to partner with their patients and community agencies.

\section{Mission of the Society of Teachers of Family Medicine}

STFM has also recognized the close interface between medical education and patient outcome, especially with respect to the many chronic diseases that family physicians manage. STFM's stated mission is to improve the health of all people through education, research, patient care, and advocacy. A major focus of the Society is in undergraduate medical education-specifically supporting family medicine faculty who coordinate or are involved in courses on teaching the doctor-patient relationship, patient interviewing and physical diagnosis, and required family medicine clinical clerkships.

\section{Future of Family Medicine Project}

The FFM Project Leadership Committee, acting upon recommendations from 5 task forces, developed 10 strategic initiatives for family medicine's future. STFM will lead Strategic Initiative No. 8, with the assistance of the Association of Family Medicine Residency Directors and the American Academy of Family Physicians. Strategic Initiative No. 8 calls for developing a comprehensive career development program to recruit and train a culturally diverse family physician workforce that meets the needs of the nation. Further, departments of family medicine are tasked to continue to develop, implement, disseminate, and evaluate best practices in expanding student interest in the specialty.

The current STFM Strategic Plan is relevant to this initiative as well as to the larger mission of the Society. To give life to this activity, the Board will ask each STFM group to embrace part of the following goals. Some of the groups will be specifically identified and asked to expand or modify their efforts. Success in achieving the goals articulated in the strategic plan can only occur if the entire membership participates.

Goal No. 1 is to continue to develop faculty for our training programs and departments. The Group on Faculty Development and the E-Learning Task Force are addressing these areas. They will seek involvement from current and past Bishop Fellows, a resource for the Society who can enrich those following behind them.

Goal No. 2 prioritizes diversity in the Society and in the discipline. Specific theme days and other presentations will be solicited by the program committee to address issues of diversity in the meetings of the Society. The new Group on Admissions will be encouraged to work with the Association of American Medical Colleges and the AAFP to identify strategies being used in various institutions that have successfully identified and developed a diverse body of trainees.

Goal No. 3 emphasized the importance of pursuing quality improvement and general competencies. The Groups on Evidence-based Medicine, Physician-Patient Interaction, Residency Education, and Patient Education will be asked to address quality improvement.

Goal No. 4 describes the need to translate the elements of the new model of family medicine into characteristics of competent family physicians, including locations where the New Model has been successfully implemented. STFM has a subcommittee of the Board developing a special session for the 2005 annual spring conference to address this goal.

Goal No. 5 focuses on information technology. The recent success of STFM in receiving funding from 
the National Library of Medicine to develop a Family Medicine Digital Resource Library will provide a major boost to the integration of information technology into our departments, our training programs, and our practices.

STFM members have the opportunity to influence large numbers of students by implementing the above strategic initiatives with students taking undergraduate medical education courses in the first 2 years through required family medicine clerkships and family medicine electives. Further, STFM members will be collaborating with other members of the family of family medicine to implement the other recommendations of the Future of Family Medicine project. Each of the 9 strategic initiatives, in addition to No. 8, was assigned to a lead organization within the family medicine family. STFM will work with these groups in addition to taking the lead on initiative No. 8.

$$
\text { Jeannette E. South-Paul, MD }
$$
STFM President

\section{References}

1. Future of Family Medicine Project Leadership Committee. The future of family medicine: a collaborative project of the family medicine community. Ann Fam Med. 2004;2(Suppl 1):S3-S32.

2. Council of Deans. Educating Doctors to Provide High Quality Medical Care. Association of American Medical Colleges. July 2004. Available at: https://services.aamc.org/Publications/index.

3. Partnerships for Quality Education, Success Stories for the Front Lines, RWJ Foundation, 2004. Available at: http://www.pqe.org. 